\title{
Entangled expertise: Women's use of social media in entrepreneurial work
}

\begin{abstract}
Social media platforms are important to self-employed cultural workers as a means of reaching markets and promoting the entrepreneur's brand identity. But beyond selfbranding, how are notions of expertise negotiated by individual cultural entrepreneurs and how does this relate to gender? This article addresses issues of identity and professionalism for women cultural entrepreneurs by focusing on their use of Twitter. Given the well documented gender and ethnic inequalities in cultural industry work, what does women's use of Twitter tell us about the nature of women's professional identities within neoliberal economies? We argue that online platforms are an important space for self-employed cultural workers and that within this context, ideas of femininity and entrepreneurship are entangled. The article concludes by discussing the value of examining social media spaces as a means of exploring the presentation of women's expertise in a postfeminist era.
\end{abstract}

Keywords: expertise, self-employed, social media, cultural entrepreneurship, feminism, post-feminism, neoliberalism, identity, women. 


\section{Introduction}

Contemporary biographies of professional women present a feminist discourse focused on a celebration of empowerment and individual agency. As McRobbie (2004, 2015) states, this neoliberal version of feminism is individualistic rather than collective, relying on one's ability to self-regulate, presenting an emancipated woman in control of her career and life. It portrays entrepreneurial actors as autonomous and their life story as a series of deliberate choices, with little recognition for the social, economic and cultural constraints in which they operate (Gill, 2007) and little acknowledgement of their professional expertise. In this article, we investigate the uses of social media as spaces for articulating and negotiating professional expertise through a feminist lens, drawing on McRobbie's work on female perfection (2015). For feminist scholars contemporary versions of feminism are closely aligned with neoliberal capitalism (Fraser, 2009, Gill, 2007, 2015; McRobbie, 2015), characterised by 'individualistic and competitive inclinations to working life, a readiness to improvise and 'rebrand"' (Morgan and Nelligan, 2015: 68) and in particular, being recognised as an expert in your sector is also advantageous (Jones, 2002) yet expertise as a concept is often taken for granted.

We focus on women entrepreneurs working in the Cultural and Creative Industries (CCls) and study their use of social media platforms. Social media has become a space in which professional expertise is communicated, and in this context, a form of entrepreneurial femininity is depicted (Duffy and Hund, 2015). To analyse cultural entrepreneurs' online profiles we combined long term observations with a focused period of time to study daily activities of a sample of women. Our study explores 
themes raised by contributors to Conor et al's collection of articles on Gender and Creative Labour (2015), but our specific focus is on depictions of expertise, selfpromoting and self-branding (Scharff, 2015) in social media practices, within an entrepreneurial context.

The use of the term 'cultural entrepreneur' is not one which is readily recognised by all cultural workers, rather, it relates to academic discourses on the subject of entrepreneurship in the CCls (Naudin, 2013; Oakley, 2014). The term 'culturepreneur' (Lange, 2006; Loaker, 2013) has been used to redefine artistic and creative practices within neoliberal regimes of work. To help us define cultural entrepreneurs, we draw on The Independents (Leadbeater and Oakley, 1999), who describe cultural entrepreneurs as individuals who are self-employed, freelancers and owners of microenterprises or who have a portfolio career and work within the so called 'creative industries' (Hesmondhalgh, 2008). The portfolio nature of their careers means that 'they do not fit into neat categories' (Leadbeater and Oakley, 1999: 11). By referring to cultural entrepreneurs we seek to situate our study within a critical discourse; a discussion which seeks to problematize the insecurities and challenges of contemporary modes of work (Ellmeier, 2003; Loaker, 2013; Oakley, 2014). Within the context of entrepreneurial $\mathrm{CCl}$ work, online platforms are utilised as an opportunity to self-consciously market oneself and construct a 'micro-celebrity' status (Marwick, 2013: 5). The public nature of online activities invites a self-conscious presentation of expertise, reflecting values and qualities connected to women's status as entrepreneurs in the CCls. We argue that in performing expertise, women's status both as entrepreneurs and as cultural workers are entangled as they negotiate female 
professional identities online. We explore the gendered aspects of their social media activity but are not concerned with comparing this to men's use of social media. This is partly because it is not necessary to explore women's identities in binary opposition or in relation to men, but their specific entrepreneurial practices in the CCls.

Evidence of gendered inequalities are apparent in studies of sub-sectors such as television and film industries (Creative Skillset, 2011, Directors UK, 2014). For instance, in their special issue on Gender and Creative Labour, Conor et al (2015) reveal the reluctance to commission work by women (Wreyford, 2015); the underrepresentation of women producers in film and television (Alacovska, 2015); and the challenges women face in negotiating branding and self-promotion (Scharff, 2015). Taking this on board, we explore how women cultural entrepreneurs present themselves as experts through social media platforms. Our analysis is organised under three key themes: 'Let's do this!'; imperfection in women's professional identities; and not Tweeting.

\section{Feminism, gender and entrepreneurship}

The entanglement of feminist and anti-feminist ideas illustrated by celebrities such as Sheryl Sandberg (Chief Operating Officer of Facebook) merge a feminist discourse of empowerment with neoliberal values, presenting a version of a 'perfect' femininity (McRobbie, 2015). Of interest to feminist scholars is the pervasiveness of a neoliberal agenda on personal identity and notions of subjectivity as individuals become preoccupied with self-image to demonstrate qualities such as their expertise. To clarify, neoliberalism is a term often used to describe contemporary political values 
attached to "anti-democratic or pro-corporate power" (Davies, 2014:310).

Characteristics of neoliberalism include privatisation of activities which lie outside the market, the state as an active force in institutions and individual conduct, and the encouragement of competition leading to inequalities (Davies, 2014:310). McRobbie (2015) in particular, is concerned with the way in which feminism has been adopted as part of a competitive individualisation synonymous with neoliberalism, rather than as a movement which seeks to contest inequalities through collective action.

In exploring women's entrepreneurial identity, we find McRobbie's (2015) analysis of striving for the 'perfect' in contemporary femininity illuminates the manner in which women entrepreneurs present themselves and their expertise as cultural workers. In this instance, the 'perfect' is understood as a heightened form of self-regulation based on an aspiration to some idea of the 'good life', extending the notion of being 'aspirational' and putting the woman in charge of her affairs (McRobbie, 2015: 10). According to McRobbie, 'perfection' has 'entered into the common currency of contemporary femininity' (McRobbie, 2015: 4) and it is captured in a 'can-do-girl' (Harris, 2004), a woman who strives for success in all aspects of her life.

McRobbie (2015) describes how the idea of perfection has entered into the realm of contemporary femininity as an aspect of the individualised project, driven by celebrities. By way of illustrating this, McRobbie draws on the US drama Girls written by Lena Dunham, highlighting how characters in the drama indirectly strives for perfection. Through irony, the programme presents the key protagonist, a character based on Dunham herself, as seeking perfection by expressing her own imperfections. 
As McRobbie states, a 'can do and must do better' (2015:16) ethos drives the imperative for perfection through constant self-monitoring, including the management of imperfection, as an aspect of contemporary female identity. Given the levels of precariousness associated with self-employment in the CCls, a gendered perspective presents a specific set of challenges (Conor et al, 2015; Gill, 2002; McRobbie, 2007), as women negotiate their position as 'expert' cultural entrepreneurs, conveying versions of their 'perfect' selves. And similar to other forms of popular culture (Levine, 2015), social media sites help to define identities such as what it means to be feminine, entrepreneurial and a cultural worker.

The entrepreneurial context enhances the need for asserting a female form of expertise given that the popular image of the entrepreneur is dominated by white male role models, embodied by internationally renowned celebrities such as Donald Trump, Mark Zuckerberg or Richard Branson. Recent academic studies are beginning to challenge this by presenting a wider range of entrepreneurial practices (Steyeart and Hjorth, 2006) exploring new narratives as an alternative entrepreneurial identity. Gendered viewpoints contest personality-based theories and seek to reveal inequalities in research and in practice by analysing stereotypes in which women are constructed as 'deviant from the (male) norm' (Tedmanson et al., 2012: 534). However, the notion of an 'alternative' identity raises questions about the space in which professional activities are enacted, potentially leaving women out from competing within broader society, for pay recognition and social status (Taylor, 2015). Academics are problematising the myth of the entrepreneur but dominant discourses associated with the white male image of the entrepreneur still prevail (Shane, 2007). 


\section{Cultural work and expertise}

Taylor and Littleton (2012) discuss the complexity of constructing and maintaining identities for cultural workers, arguing that identities are fragile and threatened by success as well as failure because of the precarity of cultural work. Women cultural workers in particular are often ascribed a 'deficit identity' (2012: 140) - a negatively positioned identity taken up by those in less privileged positions. They suggest that it is because of this deficit identity that the status of women cultural workers is likely to be challenged, and their process of identity repair and negotiation ongoing.

On social media, the repair and negotiation process is even more fragile, with the highly public nature of social media making it more difficult to maintain a coherent identity (Cover, 2012), but at the same time, providing a space for subversive potential (Cook and Hasmath, 2014). For instance, cultural work is typically constructed so that women do not become the stars or geniuses, do not have equal access to cultural work, are not equally rewarded and are subject to various forms of occupational segregation that reinforce inequalities of both recognition and reward (Sang et al., 2014). Social media platforms offer an opportunity for women to communicate their expertise to a wide audience. We consider the challenges for women in presenting themselves as expert entrepreneurial cultural workers, a perceived necessity for securing ongoing paid work (Andres and Round, 2015; Jones, 2002).

As Morgan and Nelligan argue cultural workers 'must be prepared to endure the scrutiny and arbitrary judgements of gatekeepers in those occupations where work is usually allocated informally' (2015: 68). The informality of most social media platforms 
do not negate the importance of appealing to peers, clients and key decision makers who tend to share the same online spaces. Given the opportunities social media present to entrepreneurs as a means of marketing themselves and of securing an income, how are women presenting themselves as experts through their Tweets? Expertise is often a term taken for granted in accounts of cultural work, and there is a great deal of ambiguity around what expertise is. To inform our understanding of expertise we draw on Russell Prince's definition of expertise as 'A social relation where a particular actor has authority over another actor through their possession of a particular form of knowledge.' (Prince, 2010: 6).

Many definitions of expertise commonly acknowledge that in order to be known as an expert in a field, an individual needs to have specialist knowledge and skill, but also the endorsement and approval of others (Bassett, Fotopoulou and Howland, 2013; Schudson, 2006; Turner, 2001). While self-branding tends to be a more individualistic exercise (Marwick, 2013), we argue that expertise performance takes place in a relational context. This is particularly interesting when exploring online practices which invite the use of 'retweets', 'likes' and 'replies' rather than merely broadcasting one's status update. Jones (2002) argues that being able to effectively perform one's expertise is crucial for careers in the CCls; she uses the concept of 'signalling' to describe how $\mathrm{CCl}$ workers communicate their expertise through their relationships with others, exhibiting requisite skills and their aesthetic style. This forms part of Jones' signalling expertise framework, which we draw upon both methodologically and conceptually for this research (Patel, 2017). 


\section{Method}

In order to examine expertise on social media, we carried out an online ethnography focusing on Twitter activities of six female entrepreneurs. As researchers we are actively involved on Twitter and have been observing and interacting with cultural workers for a number of years. As online ethnographers, we were able to establish the position of each entrepreneur enabling us to examine self-presentation in relation to, for instance, their profile at an international or local level. Evidence of this became apparent when investigating followers and the standing of individuals or companies who retweet them. We have followed the individuals in the sample on Twitter for the past 3 to 5 years (2010-2015), which provided some background context about each person. Over that period, our attention to what the users were tweeting is best characterised as what Kate Crawford terms "background listening" on social media, where "commentary and conversations continue as a backdrop throughout the day" (Crawford, 2009: 528). Crawford argues that even though we may pay little conscious attention to such background commentary, it still contributes to a sense of intimacy and affinity with others in social media spaces. Our position is similar to that of ethnographers, but in this case we are embedded within the digital environment to probe deeper into the online entrepreneurial practices of female cultural workers.

The process of 'listening' assisted our decision making for sampling, establishing who we would analyse and the period of time covered. Our 'listening' in to the individuals' Tweets meant that we had some background knowledge including: 
- They are cultural or media workers, self-employed and entrepreneurial in their practice;

- They are active on Twitter making use of the platform as part of their businesses;

- All of the individuals are relatively well established within their fields.

The selection process was based on years of following the entrepreneurs on Twitter and observing that they work professionally in the CCls. Furthermore, the six women were chosen partly for their active status on Twitter and their use of Twitter as a platform for presenting a proportion of work related Tweets. We were limited as to their background information, for instance social class was impossible to establish, but have been able to estimate the women's ages as ranging from early 30 s to early 50 s. The women's ethnic background included four white British women and two black AfroCaribbean British. For the second element, we collected data which focused on ten days' worth of Tweets by the six female entrepreneurs. We collected the data by taking screen shots (grabs) of all their Twitter posts across the period of time and pasting them into a word document. As researchers, we were conscious of the need to capture posts by each person as a means of 'reading' their ten day 'timeline' (the person's stream of posts seen altogether). In addition we undertook a textual analysis of their Twitter profile such as their short biographies, location, profile picture and number of followers and people they follow. Tweets often have a much wider context than the text in the Tweet itself (Barnard, 2014), so we contextualised Tweets to 
explore the nature of the 'conversation' such as responses from others including 'retweets' and 'likes' (presented on Twitter as a heart).

The process of analysing the data was a 'recursive process' (Bazeley, 2013: 12) evolving through different stages, sometimes backwards and forwards, following steps taken in a non-linear journey. Drawing on the literature and the data, the following themes helped us organise the material: voice and style, relational expertise and gender. Our analysis incorporated an adapted version of Candace Jones' (2002) signalling expertise framework (Patel, 2017) which allowed us to identify the more relational aspects of their Tweets, rather than focusing solely on self-branding and promotional practices. The framework consists of three core elements:

- Institutional context considers the institutional and economic context of signals; in the case of our participants, this also included the individual's background, some of which we gleaned from many years of 'background listening' of their activity on Twitter.

- Signalling content considers identity (the 'voice and style' aspect of our theme), performance (the 'expertise in the field and position' theme) and relationships (career relevant networks, which could include clients of the entrepreneurs, or the companies they work with).

- Signalling strategies consists of status enhancement, reputation building and impression management. 
Jones (2002) used the framework for conceptualising CCl careers, and the adapted version specifically accounts for communication on social media platforms, including Tweets, images, replies, quotes and relationships.

As Twitter is a public platform, and users should be aware that their posts can be visible to anyone, there are ongoing concerns raised in social media scholarship about the ethical considerations of using this data without users' knowledge (Rosenberg, 2010). On social media sites such as Twitter, data is freely available and easily searchable. Yet the same debates and concerns about privacy and anonymity remain (Henderson et al., 2013). As argued by boyd and Crawford: "just because it is accessible doesn't make it ethical" (2012: 671). People may be aware they are using a public forum but users sometimes do not fully understand the implications of what they post, or how far it could reach (Byron 2008; Marwick and boyd, 2010).

For these reasons, we anonymised participants by giving them pseudonyms. When conducting research on public sites such as Twitter, the identity of participants can still be revealed through a simple text search (Ess, 2002). To avoid this, any Tweets which are used as examples in this paper are significantly amended to protect our participants (Markham and Buchanan, 2012), however their meaning and relevance to our analysis will still make sense in the discussion.

\section{Findings and discussion}

Our analysis of the findings centres on women's performance of expertise within the context of contemporary feminist debates about cultural work and entrepreneurship. As we will discuss, analysing the Twitter activities of female cultural entrepreneurs 
through the 'lens' of the performance of expertise reveals the complex and relational nature of online identity formation. We present displays of expertise on Twitter under three themes: 'Let's do this!'; imperfection in contemporary professional women's identities; and not Tweeting.

\section{'Let's do this!'}

A significant factor in the cultural entrepreneurs' use of social media is the opportunity for marketing and promoting their professional status, thereby reflecting expertise. The signalling of expertise is identified in relation to their identities as entrepreneurs, as women and as $\mathrm{CCl}$ workers. Their online behaviours reflect a pro-active attitude captured in 'Let's do this', typical of a discourse which reflects the celebratory and entrepreneurial attributes (McRobbie, 2015). We single out the upbeat tone in 'Let's do this!' to suggest that a particular kind of online identity is presented, a version of expertise which tends to blur personal and professional life, and reflects high levels of personal investment in their work (McRobbie, 2016; Ucbasaran et al., 2010). In mitigating against the risks and precariousness of entrepreneurship, cultural entrepreneurs self-consciously negotiate and manage their online identities (Taylor and Littleton, 2012; Taylor, 2015; Duffy, 2015), which forms part of the 'impression management' aspect of signalling expertise.

It heralds a sliding scale of attentiveness, or what we might call a continuum of professionalism, as work oscillates between multiple mobile locations on a home/work axis. (Gregg, 2014: 122) 
Aspects of personal and professional life were mentioned on Twitter by most of our participants, for example, social media and marketing consultant Hazel, writes Tweets which often contain a very determined and rebellious tone which aim to demonstrate her work ethic.

'Having an early night. It's a brand new week soon and I mean business! X' (Hazel)

'It's getting dark in the mornings already. Morning! Okay Monday, let's do this!' (Hazel)

The Tweets were sent before Hazel went to bed and then early the next morning. There was an eight-hour gap between the two Tweets and the language she uses ('I mean business!'), suggests that Hazel's performance of expertise on social media includes a 'go get it' attitude characteristic of contemporary business women (Gray, 2003). Hazel presents herself by echoing feminist discourse utilised by Sheryl Sandberg and others, a sense of empowerment and sisterhood, targeting some of her business and digital consultancy services specifically at women and creating hashtags using words such as 'rebel' and 'bitches', often alongside selfies, expressing her confidence as a woman entrepreneur. The context for understanding Hazel's confidence is in contrast to the ways in which other forms of feminine communication online such as mummy bloggers are dismissed and 'often constructed as lightweight, frivolous, and excessively emotional' (Levine, 2015, p.1).

The uncertainties of $\mathrm{CCl}$ work encourages individuals such as Hazel to make themselves available for work at all times (Gill, 2002) and to draw on a rhetoric 
associated with 'serious' entrepreneurs (Kariv, 2012). This image is in conflict with equality rights enjoyed by most employees such as sick pay and maternity leave. It also reflects the lack of relevant data on the self-employed $\mathrm{CCl}$ work, contributing to enduring inequalities (Connor, Gill and Taylor, 2015).

Gregg highlights how the demands of modern work, exacerbated by the internet and social media contribute to the potential for self-exploitation, and how for women, this is a continuation of the traditionally normalised patterns of flexible, domestic work which took place in the home $(2008,2014)$. Like Fraser (2013) and McRobbie (2015), Gregg discusses the relationship between 'equal opportunity' feminism and the neoliberal emphasis on individuality, expressing concern about the positive images portrayed of professional women who can choose when and where they work, which reinforce a notion that women 'naturally' prefer flexible work as a means of managing a range of responsibilities such as childcare. In Hazel's case, flexibility in work includes her 'choice' to work at weekends.

'The weekends should be days of rest?! Only if you are doing stuff you have to escape from the rest of the week! (Hazel)

Evidence of self-exploitation in cultural work has been highlighted by many scholars (for example see McRobbie, 2016), but social media enables this to be publicly voiced as an aspect of one's online profile. As an expression of expertise, there appears to be a keenness to present a work ethos of being busy and hard-working, in line with neoliberal imperatives of being "mobile and malleable, infinitely energetic and 
ambitious, living in the present and ready to adapt to the immediate demands of changing markets" (Taylor, 2015:184).

On Twitter, characteristics associated with a 'Let's do this' approach can be exploited through the use of platform affordances such as hashtags, retweets and mentions which allow expertise to be performed in unique ways and are built to reach as many followers as possible. For instance, Stephanie makes a brand association with her own company's success.

'Look who's game launched iPhone 6S - [startup name]; backed by @companyname; we must be doing something right! [link]' (Stephanie)

The public nature of the performance on Twitter by entrepreneurs, means that on some level, they take into account their audience. The association with a large company such as Apple is a relational strategy which is a part of signalling expertise; communicating the association with Apple on a platform such as Twitter helps to enhance the status of Stephanie and her organisation (Jones, 2002).

Sharlene, an internationally renowned founder of a UK awards ceremony and a motivational speaker, makes the most of a Tweet by a company who are promoting her talk by retweeting it. The Tweet includes an image of a smiling Sharlene and a quote by her stating: 'the ability to identify an opportunity and act on it is the most powerful weapon of all'. This is presented alongside \#MondayMotivation and \#NeverGiveUp both of which are hashtags often associated with entrepreneurship on Twitter. For instance \#NeverGiveUp is used in Tweets which express sentiments such as 'in the middle of every difficulty lies opportunity' and aspirations relating to personal 
motivation and self-development with other hashtags such as \#RuleYourself, \#BecauseWeCan and \#BeThe1. We found evidence of Tweets by women outside of our sample which added \#women, \#mompreneur \#strong \#girls \#dreambig, to name but a few, further enhancing an upbeat rhetoric.

This also suggests that a 'Let's do this' attitude resonates with a need to belong to an online community, through hashtags and a language which conveys an enterprising positivity. While this appears to be more obviously linked to women's entrepreneurship, rather than specific to $\mathrm{CCl}$ work, the level of self-employment in the sector requires cultural entrepreneurs to engage with this language. In building their image as experts, cultural workers must become proficient in the language of social media linked to women, entrepreneurship, $\mathrm{CCl}$ work; and the combination of words, emoticons and use of hashtags to categorise Tweets. In addition, this forms part of a global conversation on Twitter which harnesses an entrepreneurial attitude with positivity. A 'can do attitude' suggests empowerment through entrepreneurship and a sense of sisterhood (Winch, 2013) asserted through mutual support by retweeting and the use of affirmative hashtags.

\section{Imperfection in contemporary professional female identities}

As women's professional identities are understood as 'other' from the male norm (Taylor \& Littleton, 2012; Thomas-Hunt and Phillips, 2004), particularly in the entrepreneurial context (Gray, 2003; Tedmanson et al., 2012), we find the language in some of the Tweets from our sample to present expertise with a level of ambiguity rather than the confidence one might expect from entrepreneurs. In contrast to the 
'Let's do this' ethos, we sometimes found a tentativeness when the women communicated their achievements or their appearances at high-profile events. For example Vanessa, a social media consultant, talks about how she is shy at a conference:

Definitely feeling that 'first day at new school' vibe at \#conference.

Ridiculously shy for no reason. (Vanessa)

Alternatively, Angie's tweet below demonstrates muddled meanings. Angie describes herself as a 'start-up expert' in her Twitter bio, and yet in some of her Tweets, she exhibits some shyness or reluctance:

Eeeek! I just did my 1st periscope, I'm not a fan of talking to the camera but for what the future holds l'd better get used to it. See you soon! (Angie)

At one level 'better get used to it' implies that Angie has some success or recognition coming her way, but this potential 'showing off' is tempered by 'Eeeek!' and 'I'm not a fan'. Angie's self-proclamation as an 'expert' in her online profile is an example of how expertise can be claimed by someone online, yet an important aspect of expertise is its recognition and legitimation from others of a higher status (Schudson, 2006; Turner, 2001).

We find a connection here between McRobbie's (2015) analysis of 'imperfection' as an aspect of female 'perfection'. The Tweets by Vanessa and Angie appear to embody dual meanings, attempting to communicate their expertise by referring to their 
attendance at conferences or being in the media, whilst downplaying their confidence to display some level of vulnerability. Winch (p. 196, 2013) argues that in a neoliberal postfeminist context, branded cultures destroy the potential for political solidarity by encouraging comparisons, admiration and feelings of envy. One interpretation of Angie's tweet could suggest a level of antagonism in her message, pointing to the potential for rivalry with others (women and men) in a bid to signal her expertise as a professional woman, someone whose career will involve 'talking to the camera'.

Studies such as Thelwall et al (2010) suggest that women are more likely to express prosocial behaviour online - "expressing joy for another but not expressing self-pride" (p.196). Moss-Racusin and Rudman (2010), Taylor (2011) and Scharff (2015) claim that the entrepreneurial imperative to self-promote is problematic for women who tend to prefer more social modes of relating online. We found that some Tweets included self-deprecating humour, which Zappavigna (2014) identifies as one of the 'key bonds' in relating with others online. For example:

That awkward moment when people keep coming up and saying hi + pretend you know who they are \#babybrain 5 years on lol (Angie)

In Zappavigna's study of the role of emotion and affect in online identity formation, she identified examples of gendered self-depreciation through use of the \#badmother hashtag. This is similar to the \#babybrain hashtag use by Angie above, suggesting a playfulness with gender norms, mocking the idea of the 'perfect mother' (Zappavigna, 2014: 218) whilst at the same time facilitating possible affiliation and interaction with other mothers who are using the same hashtag. 
Angie is not shy about presenting her glamorous entrepreneurial lifestyle in her Tweets, but by making use of the hashtag 'babybrain' as part of a tweet, she is communicating her imperfections, or 'perfection' through 'imperfection'. Of concern is Adkins' idea of gender re-traditionalization (1999) by signifying potentially gendered aspects of entrepreneurial work as different from the 'norm', namely having to manage motherhood ('babybrain') whilst retaining one's reputation as an entrepreneurial woman.

Tweets by Hazel are also peppered with personal anecdotes such as her successes in mastering water marbling effects for her nails and descriptions of her dreams of marrying a man she hardly knew. Similarly, Angie often retweets her horoscope star sign, '... has intense emotions. Intense love, intense hate, intense everything' adding symbols such as a crying face emoji to personalise the Tweet. Sharlene retweets a photograph of herself with a colleague in Italy, appearing as a 'sexy' woman striding a vespa and using the hashtag TBT (throw back Thursday). For female $\mathrm{CCl}$ entrepreneurs, social media offers a space for communicating the narratives they seek to present to themselves and their followers (Taylor \& Littleton, 2012), as distinctively female alongside professional and entrepreneurial. For women entrepreneurs, the individualization presented through contemporary work practices, could relieve us from the constraints of traditional roles in labour markets (Adkins, 1999), creating opportunities to negotiate new identities. However, Adkins argues that 'far from being transgressive of the social categories of gender, individualization may re-embed 'women' in new socialities' (1999: 136). By describing the 'retraditionalization of gender' (1999: 129) in individualised work, gender demarcations might be just as 
significant. Online spaces are a playing field for developing one's identity as an entrepreneurial cultural worker, encouraging peer recognition in an environment where social and professional status are not reliant on the office dynamic but conscious of an imagined audience (Marwick and boyd, 2010). It is a milieu in which individuals tell the 'story' of themselves as a significant aspect of how they choose to perform their expertise, and in this case, it is wrapped up with notions of how they seek to present the 'feminine' as an aspect of their professional selves.

At a conference, Hazel negotiates Tweets relating to having apparently cried on stage during her keynote presentation. Given Hazel's usual online personae as a confident, 'Let's do this' entrepreneur, the Tweet below reveals how she manages what could be perceived as a weakness, namely crying on stage during her keynote speech.

I'm making a video about how @ $\mathrm{t}^{* * * * *} \mathrm{~g}$ made me cry when I was on stage after my keynote at @ $T^{\star \star \star * *} d$ last week! :D \# $T^{\star * \star * 2015 ~(H a z e l) ~}$

Does that jeopardise her performance of expertise as an entrepreneurial worker? Through this Tweet, Hazel is re-claiming her emotional outpouring as a way of managing her online profile, which in turn becomes part of her performance of expertise, by producing a video response. Is this damage limitation? In these Tweets, Hazel feels it is necessary to regain control and she chooses to highlight her experience of crying on stage, incorporating a laughing emoticon. Hazel's 'imperfection' is transformed into a signal to demonstrate self-awareness and control over her image. The context for this Tweet is a set of other Tweets relating to the significance of the event, to crying, to the positive impact of Hazel's keynote Tweeted 
by others, liked several times and retweeted by Hazel. This resonates with a need for women to disclose forms of intimacy (Berlant, 1998), and emotional work (Hochschild, 1979) which suggests a specifically feminine discourse, connected through hashtags or replies on Twitter, constituting part of their performance of expertise. The disclosure of emotion online plays an important role in forming connections and relationships (Cote and Pybus, 2007). Kuntsman (2012) notes how naming emotions online can create "communities of feelings" (p.6), and such affective communication online is particularly common among women. For instance, Sharlene seeks to present herself as appreciative of others by 'liking' and retweeting a tweet of a female colleague thanking her, for thanking her. This overzealous demonstration of thanks between the two women indicates the dual impact of communicating on Twitter: a demonstration of a personal sentiment in a public space, with its imagined audience.

However, being able to engage in these communities of feelings requires an engagement with and adherence to certain online conventions and practices, fostered by both users and platforms themselves, and a failure to adhere to such conventions can be a disadvantage. Thus despite the egalitarian promise of online spaces for performing expertise, they also potentially reproduce inequalities and exclusion (Jensen, 2013). By including a discussion on 'Not Tweeting' we seek to reveal the challenges in navigating a public space such as Twitter.

\section{Not Tweeting}

The pro-active approach demonstrated by Hazel and Angie is not evident in all the women cultural entrepreneurs we sampled. In contrast, Sharlene and Siobhan mainly 
used the retweeting function to display their expertise. Sharlene retweeted Tweets from either her own company's account, or from companies who have hired her as a motivational speaker. These are examples of status enhancement by retweeting endorsements (as Hazel did) and also, like Stephanie, displaying her expertise by association with the success of her own company.

Siobhan, a film producer, mainly retweeted posts related to her industry sector, film, and through her retweets she appears as someone 'in the know', but there is very little about her own work and success. This appears to be a more altruistic approach to performing expertise - Siobhan is sharing events and opportunities for others, displaying her knowledge of the film industry and the nature of her networks.

Yet, what Siobhan is not doing on Twitter is perhaps just as revealing. As we have stated, presenting one's expertise as an entrepreneurial worker is a significant aspect of securing work but the opposite could also be true. In other words, despite the perceived need to market oneself online, some women cultural entrepreneurs might choose to limit communication to retweets, avoiding 'micro-celebrity' practices and 'oversharing' (Marwick and boyd, 2010). We suggest that if we accept the use of social media as a space for self-conscious identity performances, refraining from Tweeting is also a controlled performance, whether that be out of shyness, a reluctance to engage too much with the technology or to protect one's professional identity. Although our women cultural entrepreneurs appear to know some of their followers, there is a degree to which they are also presenting themselves to an audience whose positive or negative Twitter responses are unpredictable. This lack of full control is pertinent to the 
presentation of expertise as a relational phenomenon but also plays into the hands of the deficit identity of women cultural workers (Taylor and Littleton, 2012) and challenges associated with being deviant from the 'norm' as a female entrepreneur (Tedmanson et al., 2012).

As Smith (2009) argues, the demonisation of the 'diva' female entrepreneur in the media suggests a problem for women entrepreneurs who appear to reflect traditionally male characteristics. Perhaps it is this image of the 'diva entrepreneur' that some women try to avoid, so that either their expertise is communicated in a more palatable manner. Equally, simply abstaining from actively developing an online profile impedes the possibility of others manipulating or interacting with women's professional identity. This outcome suggests that in limiting their use of platforms such as Twitter, some women are holding back from advancing their professional identity as expert cultural entrepreneurs (Taylor and Littleton, 2012).

\section{Conclusion}

In this article we explored Angela McRobbie's notion of the entanglement of feminism (2004) and the idea of striving for the perfect/imperfect in contemporary femininity (2015) as a framework for illuminating how women cultural entrepreneurs present themselves on social media. The manner in which our cultural entrepreneurs negotiate an 'imagined audience', as part of the ongoing work of presenting a professional identity varies depending on the individual but we find evidence of a gendered perspective. The self-conscious decisions to refrain from Tweeting or the use of hashtags to make meaning more ambiguous, resonates with feminist discourses. 
Presenting oneself as an expert is burdened with the potential lack of professional identity for entrepreneurial women and more specifically for those working in the CCls. The blurring of the personal and professional is connected to a non-stop 'can do' culture - which we characterise as the 'Let's do this' imperative - is expressed online as an aspect of one's dedication and hard working credentials.

We find that in performing expertise, women's professional identity is ongoing, relational work. As a platform, Twitter reinforces opportunities for an expression of expertise through the use of retweets, 'likes', replies and an awareness of an imagined audience. Given the degree to which social media can be important for securing entrepreneurial work in the cultural industries, we argue that the character of women's online activities require further scrutiny. Our approach combines a familiarity with the platform and the characters in our sample with a focus on a specific period of time to analyse the daily lived experience of presenting and sustaining a professional identity and performance of expertise. The notion of an 'entangled' expertise reflects how women are caught up in diverse narratives when presenting their professional identities. Women draw on feminist discourses of empowerment, demonstrating an entrepreneurial 'can do' attitude but this is interwoven with affective strategies such as expressing emotion or admitting vulnerability through a self-conscious use of relevant hashtags. It is difficult to claim from our research whether this contributes to gender inequalities in the cultural sector, but we argue that at the very least, women's expertise as it is presented online is 'feminine', often muddled with other identities and appearing to exhibit less of the professional confidence which we might have anticipated from entrepreneurial 'experts'. 


\section{References}

Adkins, L. (1999). Community and Economy A Retraditionalization of Gender? Theory, Culture \& Society, 16(1), 119-139.

Alacovska, A. (2015). Genre anxiety: women travel writers' experience of work. The Sociological Review, 63(S1), 128-143.

Andres, L., \& Round, J. (2015). The creative economy in a context of transition: A review of the mechanisms of micro-resilience. Cities, 45, 1-6.

Barnard, S (2014) 'Tweet or be sacked': Twitter and the new elements of journalistic practice. Journalism 1-18.

Bassett, C., Fotopoulou, A. and Howland, K. (2013) Expertise: a scoping study. Working Papers of the Community and Cultures Network Vol. 1 April 2013. Available at: http://2plqyp1e0nbi44cllfr7pbor.wpengine.netdna-cdn.com/files/2013/04/Sussexscoping-report.pdf. [Accessed 14/12//2016].

Bazeley, P. (2013). Qualitative data analysis: Practical strategies. Sage.

boyd, D., \& Crawford, K. (2012). Critical Questions for Big Data. Information, Communication \& Society, 15(5), 662-679.

Berlant, L. (1998). Intimacy: A Special Issue, Critical Enquiry, 24(2), 281-288.

Byron, T. (2008). Safer children in a digital world: The report of the Byron review. Available at https://www.gov.uk/government/groups/uk-council-for-child-internetsafety-ukccis [Accessed 15 December 2015]. 
Creative Skillset. (2011). Turning Out: Women in the UK radio industry. London: Skillset.

Conor, B., Gill, R., \& Taylor, S. (2015). Gender and creative labour. The Sociological Review, 63(S1), 1-22.

Cook, J., \& Hasmath, R. (2014). The discursive construction and performance of gendered identity on social media. Current Sociology, 62(7), 975-993.

Cover, R. (2012). Performing and undoing identity online: Social networking, identity theories and the incompatibility of online profiles and friendship regimes.

Convergence: The International Journal of Research into New Media Technologies, 18(2), 177-193.

Crawford, K. (2009). Following you: Disciplines of listening in social media. Continuum: Journal of Media \& Cultural Studies, 23(4), 525-535.

Davies, W. (2014). Neoliberalism: A Bibliographic Review. Theory, Culture \& Society, 31(7/8), 309-317.

Directors UK. (2014) Women Directors in British Television Production. In Directors UK [online] available at https://www.directors.uk.com/campaigns/women-directors-

\section{campaign}

Duffy, B. E. (2015). The romance of work: Gender and aspirational labour in the digital culture industries. International Journal of Cultural Studies, 1-17. 
Duffy, B. E., \& Hund, E. (2015). "Having it All" on Social Media: Entrepreneurial Femininity and Self-Branding Among Fashion Bloggers. Social Media + Society, 1(2), 2056305115604337.

Ellmeier, A. (2003). Cultural entrepreneurialism: on the changing relationship between the arts, culture and employment1. The International Journal of Cultural Policy, 9(1), 316.

Ess, C. (2002) Ethical Decision-Making and Internet Research Recommendations from the AoIR Ethics Working Committee [pdf]. Available at:

http://aoir.org/reports/ethics.pdf [Accessed 12 December 2015].

Ezzedeen, S. R., \& Zikic, J. (2012). Entrepreneurial experiences of women in Canadian high technology. International Journal of Gender and Entrepreneurship, 4(1), 44-64.

Fraser, N (2013) 'How Feminism became capitalism's handmaiden - and how to reclaim it' in The Guardian [online] available at http://www.theguardian.com/commentisfree/2013/oct/14/feminism-capitalisthandmaiden-neoliberal?CMP=share btn link Fraser (2009) Feminism, Capitalism and the Cunning of History in The New Left Review [online] available at http://newleftreview.org/ll/56/nancy-fraser-feminismcapitalism-and-the-cunning-of-history 
Gill, R. (2015) Postfeminist sexual culture. in C. Carter, L. Steiner, L. McLaughlin, eds. The Routledge companion to media \& gender, London New York: Routledge, pp. 589599

Gill, R. (2007). Critical Respect: The Difficulties and Dilemmas of Agency and 'Choice' for Feminism. European Journal of Women's Studies, 14(1), 69-80.

Gill, R. (2002). Cool, creative and egalitarian? Exploring gender in project-based new media work in Euro. Information, communication \& society, 5(1), 70-89.

Goffman, E. (1959) The presentation of self in everyday life. New York: Doubleday. Gray, A. (2003). Enterprising femininity: New modes of work and subjectivity. European Journal of Cultural Studies, 6(4), 489-506.

Gregg, M. (2014) Presence Bleed: Performing Professionalism Online. In: M. Banks, R. Gill and S. Taylor, eds. Theorizing Cultural Work: Labour, Continuity and Change in the Cultural and Creative Industries. London: Routledge, 122-135.

Gregg, M. (2008). The Normalisation of Flexible Female Labour in the Information Economy. Feminist Media Studies, 8(3), 285-299.

Harris, A. (2004). Future girl: Young women in the twenty-first century. Psychology Press.

Henderson, M., Johnson, N. F., \& Auld, G. (2013). Silences of ethical practice: Dilemmas for researchers using social media. Educational Research and Evaluation, 19(6), 546-560. 
Hesmondhalgh, D. (2008). Cultural and creative industries. In: The SAGE handbook of cultural analysis. Thousand Oaks, CA: SAGE, pp. 553-569.

Hesmondhalgh, D. and Baker, S. (2011) Creative labour: Media work in three cultural industries (London: Routledge).

Hochschild, A. (1979) Emotion Work, Feeling Rules, and Social Structure. American Journal of Sociology, 85 (3). pp. 551-575.

Jensen, T. 2013. "'Mumsnettiquette': Online Affect Within Parenting Culture”. In C. Maxwell and P. Aggleton (eds.) Privilege, Affect and Agency: Understanding the Production and Effects of Action.

Jones, C. (2002). Signaling expertise: How signals shape careers in creative industries. Career Creativity: Explorations in the Remaking of Work, (May 1998), 209228.

Kavin, D (2012) Female Entrepreneurship and the New Venture Creation. (London: Routledge).

Kuntsman, A. (2012). Introduction. In A. Karatzogianni and A. Kuntsman (eds.) Digital Cultures and the Politics of Emotion: Feelings, Affect and Technological Change. Basingstoke: Palgrave Macmillan, pp. 1-20.

Lange, B. (2006) From Cool Britannia to Generation Berlin? Geographies of Culturepreneurs and their Creative Milieus, in Berlin, in Eisenberg, C., Gerlich, R. and 
Handke, C. (eds.) Cultural Industries: The British Experience in International Perspectives, (Humboldt Universitat zu Berlin.):145-172.

Leadbeater, C. and Oakley, K., (1999). The Independents: Britain's new cultural entrepreneurs. London: Demos.

Leonard, S. and Negra, D. (2015) “After Ever After: Bethenny Frankel, Self-Branding, and the "New Intimacy of Work"”. In E. Levine (ed.) Cupcakes, Pinterest, and Ladyporn: Feminized Popular Culture in the Early Twenty-First Century (Chicago: University of Illinois): 196-214.

Levine, E. (ed.) (2015) Cupcakes, Pinterest, and Ladyporn: Feminized Popular Culture in the Early Twenty-First Century (Chicago: University of Illinois)

Loaker, B. (2013) Becoming 'culturepreneur': How the neoliberal regime of truth affects and redefines artistic subject positions, Culture and Organisation, 19(2):124145.

Markham, A. N., \& Buchanan, E. (2012). Ethical Decision-Making and Internet Research: Recommendations from the AolR Ethics Working Committee [pdf]. Available at: http://aoir.org/reports/ethics2.pdf [Accessed 01 June 2016]. Marwick, A. E. (2013). Status Update: Celebrity, Publicity, and Branding in the Social Media Age. Yale University Press.

Marwick, a. E., \& Boyd, D. (2010). I tweet honestly, I tweet passionately: Twitter users, context collapse, and the imagined audience. New Media \& Society, 13(1), 114-133. 
McRobbie, A. (2016). Be creative: Making a living in the new culture industries. John Wiley \& Sons.

McRobbie, A. (2015). Notes on the Perfect: Competitive Femininity in Neoliberal Times. Australian Feminist Studies, 30(83), 3-20.

McRobbie, A. (2009). The aftermath of feminism: Gender, culture and social change. Sage.

McRobbie, A. (2007). Top Girls? Cultural Studies 21 (4): 718 -737

McRobbie, A. (2004). Post-feminism and popular culture. Feminist media studies, 4(3), 255-264.

Morgan, G., \& Nelligan, P. (2015). Labile labour-gender, flexibility and creative work. The Sociological Review, 63(S1), 66-83.

Moss-Racusin, C.A. and Rudman, L. A., (2010), 'Disruptions in women's selfpromotion: the back- lash avoidance model', Psychology of Women Quarterly, 34 (2): 186-202.

Naudin, A. (2013) 'Media enterprise in higher education: a laboratory for learning' in Ashton, D. and Noonan, C. (eds.) Cultural Work and Higher Education. (Palgrave Macmillan).

Oakley, K. (2014) ‘Good work? Rethinking cultural entrepreneurship”. In C. Bilton and S. Cummings (2014) Handbook of Management and Creativity (Cheltenham: Edward Elgar): 145-159. 
Parker, R. and Pollock, G. (1981) Old Mistresses: Women, Art and Ideology, Routledge.

Patel, K. (2017) Expertise and Collaboration: Cultural workers' performance on social media. In: Graham, J. and Gandini, A. (eds.) Collaborative Production in the Creative Industries. London: University of Westminster Press, pp. 157-176.

Prince, R. (2010). "Fleshing out" expertise: the making of creative industries experts in the United Kingdom, Geoforum, 41(6), 875-884.

Rosenberg, A. (2010). Virtual world research ethics and the private/public distinction. International Journal of Internet Research Ethics, 3(1), 23-37.

Sang, K.J., Dainty, A.R. and Ison, S.G., 2014. Gender in the UK architectural profession:(re) producing and challenging hegemonic masculinity. Work, Employment \& Society. 28(2), 247-264.

Scharff, C. (2015). Blowing your own trumpet: exploring the gendered dynamics of self-promotion in the classical music profession. The Sociological Review, 63(S1), 97112.

Schudson, M. (2006). The trouble with experts-and why democracies need them. Theory and Society, 35(5-6), 491-506.

Smith, R. (2009). The Diva storyline: an alternative social construction of female entrepreneurship. International Journal of Gender and Entrepreneurship, 1(2), 148163. 
Steyaert, C., \& Hjorth, D. (2006). Introduction: what is social in social entrepreneurship?. In Entrepreneurship as social change: A third movement in entrepreneurship book, 1-20. Edward Elgar Publishing.

Shane, S. (2008) The Illusions of Entrepreneurship: The costly myths that entrepreneurs, investors and policy makers live by, (New Haven: Yale University Press).

Taylor, S. (2015). A new mystique? Working for yourself in the neoliberal economy. The Sociological Review, 63(2015), 174-187.

Taylor, S. (2011), 'Negotiating oppositions and uncertainties: gendered conflicts in creative identity work', Feminism \& Psychology 21(3): 354-371.

Taylor, S. and Littleton, K. (2012) Contemporary Identities of Creativity and Creative Work. Farnham: Ashgate.

Tedmanson, D., Verduijn, K., Essers, C. and Gartner, W.B. (2012) 'Critical perspectives in Entrepreneurship Research', Organization, 19, (5): 531-560.

Thelwall, M., Wilkinson, D., \& Uppal, S. (2010). Data mining emotion in social network communication: Gender differences in MySpace. Journal of the American Society for Information Science and Technology, 61(1), 190-199.

Thomas-Hunt, M. C., \& Phillips, K. W. (2004). When what you know is not enough: Expertise and gender dynamics in task groups. Personality and Social Psychology Bulletin, 30(12), 1585-1598.

Turner, S. (2001). What is the Problem with Experts? Social studies of science, 31(1), $123-149$ 
Ucbasaran, D., Westhead, P., Wright, M. and Flores, M. (2010) The nature of entrepreneurial experience, business failure and comparative optimism. Journal of Business venturing, 25, 541-555.

White, M. (2015) Women's Nail Polish Blogging and Femininity: 'The girliest you will ever see me'. In Levine, E (ed) Cupcakes, Pinterest and Ladyporn: Feminized Popular Culture in the Early Twenty-First Century, (University of Illinois Press): 137-156. Winch, A (2013) Girlfriends and Postfeminist Sisterhood Basingstoke: Palgrave Macmillan

Wreyford, N. (2015). Birds of a feather: informal recruitment practices and gendered outcomes for screenwriting work in the UK film industry. The Sociological Review, 63(S1), 84-96.

Zappavigna, M. (2014). Enacting identity in microblogging through ambient affiliation. Discourse \& Communication, 8(2), 209-228. 